\title{
Identifying desertification risk areas using fuzzy membership and geospatial technique - A case study, Kota District, Rajasthan
}

\author{
Arunima Dasgupta ${ }^{1, *}$, K L N Sastry ${ }^{1}$, P S Dhinwa ${ }^{1}$, \\ V S RATHORE ${ }^{2}$ and M S NATHAWAT ${ }^{3}$ \\ ${ }^{1}$ Space Applications Centre, ISRO, Ahmedabad, India. \\ ${ }^{2}$ Birla Institute of Technology, Mesra, Ranchi 835 215, India. \\ ${ }^{3}$ Indira Gandhi National Open University, New Delhi 110 068, India. \\ *Corresponding author.e-mail: darunima83@gmail.com
}

\begin{abstract}
Desertification risk assessment is important in order to take proper measures for its prevention. Present research intends to identify the areas under risk of desertification along with their severity in terms of degradation in natural parameters. An integrated model with fuzzy membership analysis, fuzzy rulebased inference system and geospatial techniques was adopted, including five specific natural parameters namely slope, soil pH, soil depth, soil texture and NDVI. Individual parameters were classified according to their deviation from mean. Membership of each individual values to be in a certain class was derived using the normal probability density function of that class. Thus if a single class of a single parameter is with mean $\mu$ and standard deviation $\sigma$, the values falling beyond $\mu+2 \sigma$ and $\mu-2 \sigma$ are not representing that class, but a transitional zone between two subsequent classes. These are the most important areas in terms of degradation, as they have the lowest probability to be in a certain class, hence highest probability to be extended or narrowed down in next or previous class respectively. Eventually, these are the values which can be easily altered, under extrogenic influences, hence are identified as risk areas. The overall desertification risk is derived by incorporating the different risk severity of each parameter using fuzzy rule-based interference system in GIS environment. Multicriteria based geo-statistics are applied to locate the areas under different severity of desertification risk. The study revealed that in Kota, various anthropogenic pressures are accelerating land deterioration, coupled with natural erosive forces. Four major sources of desertification in Kota are, namely Gully and Ravine erosion, inappropriate mining practices, growing urbanization and random deforestation.
\end{abstract}

\section{Introduction}

Desertification, the land degradation in drylands, has become an alarming global environmental issue. Areas affected by desertification processes lose progressively their level of biological quality and productivity. This is one of the major challenges that countries are facing in 21st century.
Desertification is 'Land degradation in arid, semiarid and dry sub-humid areas resulting from various factors including climatic variations and human activities', where 'Land' is defined as terrestrial bio-productive system and 'land degradation' is defined as reduction or loss in biological and economic productivity (UNCCD 1994). Very recently, LADA has further developed this definition

Keywords. Desertification risk; fuzzy membership analysis; normal density function; fuzzy rule-based interference system. 
as 'the reduction in the capacity of the land to provide ecosystem goods and services, over a period of time, for its beneficiaries'. 'Ecosystem goods' are products of land, which have an economic and/or social value, including land availability, animal and plant production, soil health and water quantity and quality. 'Ecosystem services' include biodiversity and the maintenance of hydrological, nutrient and carbon cycles (LADA 2011). In particular, dryland ecosystems, which are the areas having aridity index less than 0.65 (UNEP 1997), are more prone to desertification. Drylands cover around one third of the world's land area that are extremely vulnerable to over-exploitation and inappropriate land use. Drylands are home to more than $38 \%$ of the total global population (MA 2005; Reynolds et al. 2007; UNCCD 2008). Most likely, the true level of degradation in drylands lies somewhere between 10\% (MA 2005) and 20\% (GLASOD 1990), and over 250 million people are directly affected by land degradation (Reynolds et al. 2007; UNCCD 2008).

The present research was carried out with an objective to identify areas under the risk of desertification along with their severity in terms of degradation in natural parameters. The study adopted an integrated model with fuzzy membership analysis and geospatial techniques. The model would help to locate the vulnerable areas along with their risk severity in order to mitigate the effects of desertification. The conventional way to classify parameters for land degradation is by defining classes with certain lower and upper limit values and assigns the parameter-values to suitable classes. For socio-economic classification this system may suit, as most of them are discrete values derived for certain administrative boundaries. But natural parameters are continuous and there remain some representative values in transitional areas between two classes. If observed in GIS environment, a considerable number of polygons can be found out which do not exactly represent a particular class of value, but a transitional zone. These are the most important areas in terms of degradation, as they have the lowest probability to be in a certain class, hence highest probability to be extended or narrowed down in next or previous class respectively. Corrective methods should be applied to these vulnerable areas to make them less vulnerable (Sasikala et al. 2001). Thus, to embrace the variability of natural parameters like slope, soil depth, pH, texture and NDVI (the five parameters taken care of in this study) fuzzy membership approach is a viable option for risk categorization. Additionally, the use of remote sensing techniques and GIS along with fuzzy logic to evaluate the degree of risk would help an expert in very efficient planning of resource allocation and decision making.

\section{Study area}

Kota district in Rajasthan, India, was selected as the study area (figure 1 ). The district extends from $24^{\circ} 32^{\prime}$ to $25^{\circ} 51^{\prime} \mathrm{N}$ in latitude and from $75^{\circ} 37^{\prime}$ to $76^{\circ} 35^{\prime} \mathrm{E}$ in longitude. It covers an area of $5217 \mathrm{~km}^{2}$, of which $4906.95 \mathrm{~km}^{2}$ is rural area and $310.05 \mathrm{~km}^{2}$ is urban area. The district is bounded by Bundi District in north, Bara District in east, Jhalawar District in south and Chittorgarh District in west. The total population is $19,50,491$, which is $2.48 \%$ of the state of Rajasthan, of which $77.48 \%$ are literate (Census 2011). There are five subdivisions namely Kota, Digod, Itawa, Sangod and Ramganjmandi and five tehsils namely Ladpura, Digod, Pipalda, Sangod and Ramganjmandi with 874 villages in Kota district.

Physiographically, different morphological features can be observed in Kota, starting from mountains of Aravalli Range in south, lakes or reservoirs like Kishore Sagar, Sur Sagar, Jawahar Sagar and Dheba Lake in the middle, riverines and gullies of rivers like Chambal, Kalisindh and Parwan, in north, east and west. In the southern part of the district, there lie Aravalli ranges that are totally deforested and exposed where water erosion in the form of sheet erosion is predominant. Presence of desertification processes is also observed in northern part of the district where water erosion in the form of gullies and ravines on the banks of rivers Chambal and Kalisindh is rampant.

Kota district lies in hot, semi-arid (moist) with dry summers and mild winters agro-climate subregion. The mean annual temperature ranges from $24^{\circ}$ to $25^{\circ} \mathrm{C}$ rising to a maximum of $38^{\circ}-40^{\circ} \mathrm{C}$. The mean annual rainfall ranges from 800 to $1000 \mathrm{~mm}$ (Velayutham et al. 1999).

Kota is the trade centre for an area in which cotton, millet, wheat, coriander and oil seeds are grown; industries include cotton and oil seed milling, textile weaving, distilling, dairying, and the manufacture of metal handcrafts. Kota also has an extensive industry of stone polishing of a particular kind of limestone called 'Kota Stone'. It is a cheap alternative to marble. Kota's economy today is driven by the all-India fame of its coaching classes.

\section{Data used}

Satellite images of post-monsoon season (8 October, 2010), along with other ancillary information were used for identifying desertification risk areas of Kota district in Rajasthan as shown in table 1. The forest types of Kota district belong to mainly two different forest type groups, namely Tropical Dry Deciduous and Tropical Thorn Forests (ISFR 2011). Thus the forest will shed all their leaves in 

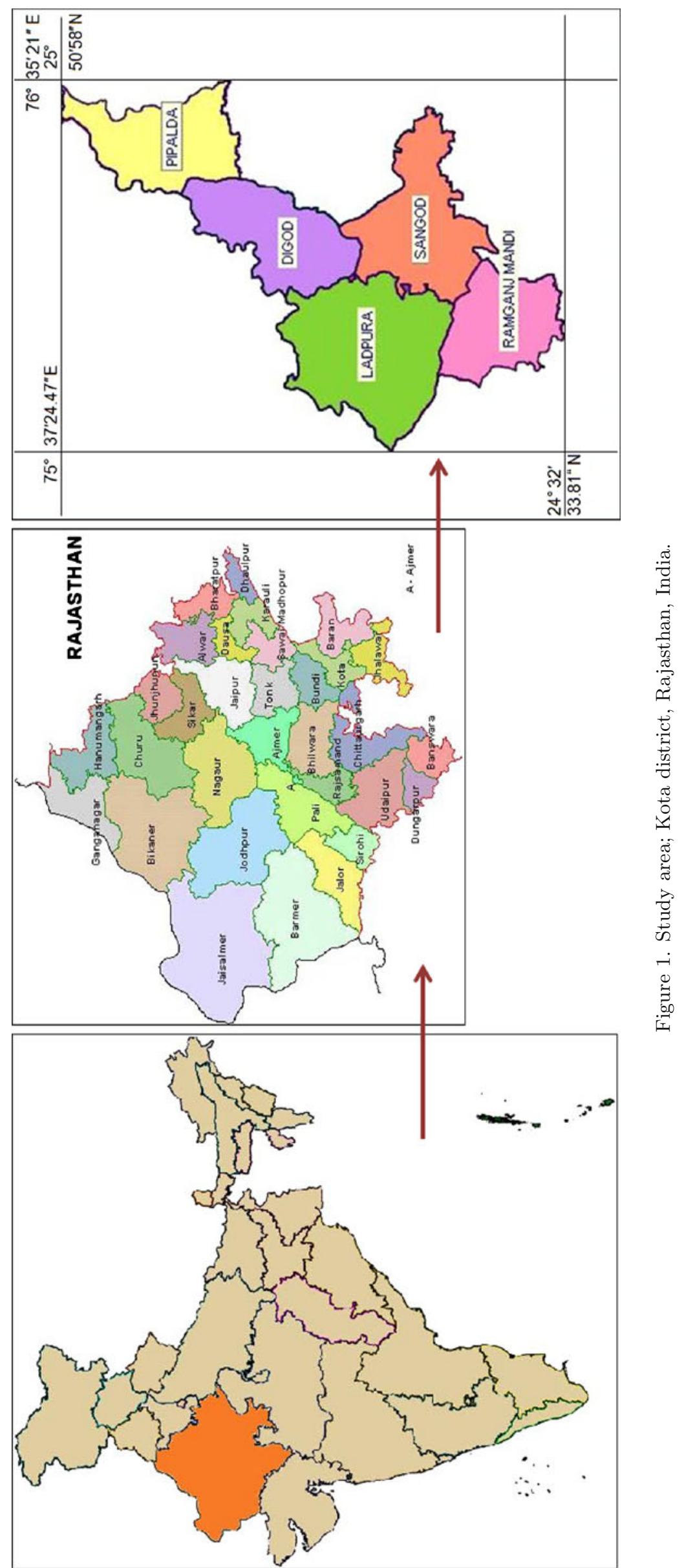
Table 1. Data specifications.

\begin{tabular}{llll}
\hline Data & \multicolumn{1}{c}{ Specifications } & Year & Source \\
\hline Toposheet & $45-\mathrm{O} / 12,15,16,45-\mathrm{P} / 9,13,14,54-\mathrm{C} / 1-11$, & 1971 & SOI \\
& $54 \mathrm{D}-1,2,5,6,9,10,11,13,14,15$. & & \\
& Scale is 1:50000 & & \\
Images & LISS III, spatial resolution 23 meter & 2010 & IRS P6 \\
Soil data & Depth in meter, pH values & 2001 & NNRMS \\
\hline
\end{tabular}

winter. To get exact vegetation vigour, the images of post-monsoon season was selected for NDVI analysis.

\section{Methodology}

There are many qualitative and quantitative methods for the complex risk assessment. The conventional way to classify parameters for environmental degradation or land degradation is to define classes with certain lower and upper limit values and assign the parameter values to suitable classes. However, it is necessary to point out, that the natural risk assessment is done under subjective and uncertain conditions. The intelligent methods are an appropriate tool for natural risk assessment. These methods using the fuzzy logic theory provide adequate processing of the expert knowledge and uncertain quantitative data (Zlateva et al. 2005). Inherently qualitative features of indicators are rather quantitative values, which are usually represented by linguistic variables. Information and decision are closely linked and different methods exist to make a decision on the basis of imperfect information. Expertise is always required to define the types of possible phenomena, to assess the natural hazard and risk levels and to propose prevention measures. In fuzzy logic system, the input linguistic variables (individual parameters) are represented and assessed by using bell-shaped membership functions. The fuzzy logic system immediate output (individual risk assessment) was derived from the tell end parts of the bell-shaped fuzzy membership functions and were described as 'low', 'moderate' and 'high'. The final fuzzy logic system output (complex risk assessment) was derived from the fuzzy interference rule based on expert knowledge. Interference rules were defined through IF-THEN clause. The overall methodology is shown in the form of a flowchart in figure 2.

The study was carried out in two inter-related stages. First stage involved identifying the risk areas in terms of individual natural parameters using fuzzy membership analysis. Second stage involved identifying overall desertification risk areas using fuzzy rule-based interference system.

In the first stage, six natural parameters, specifically, aridity, slope, soil pH, soil depth, soil texture and NDVI were used for climate, terrain, soil and vegetation analysis, respectively. Assuming the aridity ${ }^{1}$ of the whole district as homogeneous, a single aridity value that is 0.35 , was taken for the entire study area. 0.35 is the mean value of the total range of aridity of semi-arid region that is from 0.20 to 0.50 . Other parameters were classified into three classes. The total range of values of a single parameter is assumed to have mean as $\mu$ and standard deviation as $\sigma$, with $x$ being a single variable. Classes were made dividing the total range of values according to their deviation from mean. Thus the classes are:

$$
\begin{array}{ll}
\text { Class 1: } & x \leq \mu-\sigma \\
\text { Class 2: } & \mu-\sigma<x \leq \mu+\sigma \\
\text { Class 3: } & x>\mu+\sigma
\end{array}
$$

Then the distribution of each class of a single parameter was assumed to be Gaussian with $\mu$ mean and $\sigma$ standard deviation. Normal probability density function was used to obtain the membership of individual variable to be in a particular class, following the statistical formula:

$$
f(x, \mu, \sigma)=\frac{1}{\sigma \sqrt{2 \pi}} * e^{-(x-\mu)^{2} / 2 \sigma^{2}}
$$

where $x$ is the value or an individual member of a class of chosen parameter, $\mu$ is the arithmetic mean and $\sigma$ is the standard deviation of the class. Choice of normal probability density function implies that

\footnotetext{
${ }^{1}$ The term aridity came from Latin word arere which means 'to be dry'. Several formulae have been suggested for calculating the index of aridity. The Atlas of Desertification adopted the simple formula: Index of aridity $=$ rainfall $(\mathrm{mm}) /$ potential evapotranspiration. The areas having aridity less than 0.65 are called drylands. Drylands are accordingly classified in four classes namely hyper arid, arid, semi-arid and dry sub-humid having characteristic aridity values of $<0.05,0.05-0.2,0.2-0.5$ and $0.5-0.65$, respectively (UNEP 1997).
} 


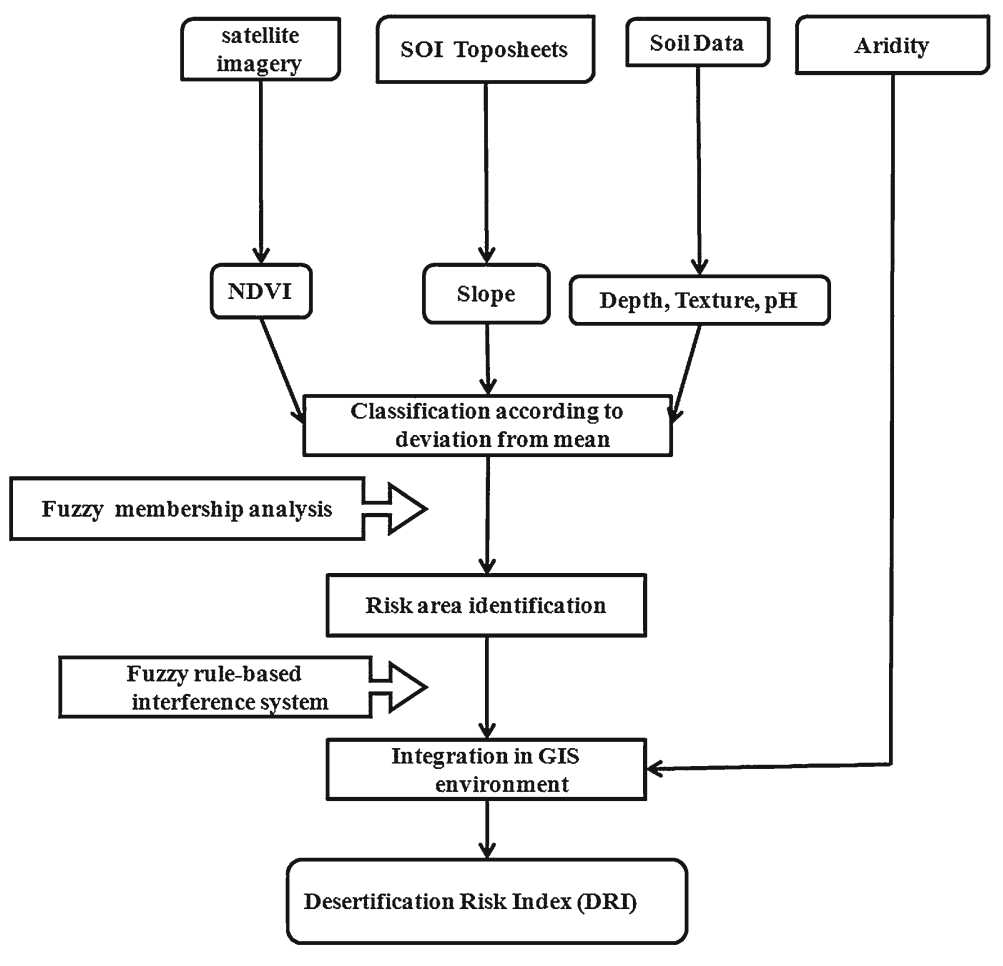

Figure 2. Methodology flowchart.

there is infinite distribution tail, typically represented by the values beyond $\mu+2 \sigma$ and $\mu-2 \sigma$. These are not representing a certain class, but a transitional zone between two successive classes, indicating the most important areas in terms of degradation, as they have the lowest probability to be in a certain class, hence highest probability to be extended or narrowed down in next or previous class respectively. The risk classes were identified in between two successive classes from the bell-shaped graph of the normal density function. The values lying in between $\mu+2 \sigma$ of the previous class and $\mu-2 \sigma$ of the next class were considered as vulnerable and identified as the risk area.

A detailed explanation implied that, for each of the class of a single parameter, there are some values more than $\mu+2 \sigma$ and less than $\mu-2 \sigma$, not strongly representing that particular class but a transitional zone between two successive classes. If we consider a threshold ranging from $\mu-2 \sigma$ of previous class to $\mu+2 \sigma$ of the next class, the values falling in this threshold are considered to be in risk. These values are referring a transitional zone, hence are susceptible to be altered easily to a higher value, if unchecked. In other words, these are vulnerable areas for degradation. Thus the vulnerable areas whose degradation can be narrowed down easily could be spotted and proper corrective methods could be planned and implemented. In case of Kota, due to less variability, the values lesser than $\mu-\sigma$ and greater than $\mu+\sigma$ were considered as risk areas.

There are few reasons which justify the use of this particular membership function. First of all, Gaussian distribution is suitable for continuous variable and for natural parameters that are continuous in nature. Normal distribution permits satisfactory approximations of the variables which are in continuous distribution, where the relative frequency of the variate varies continuously as the variate itself varies continuously over the range (Goodman 1967). Secondly, the identification of vulnerable areas is very straightforward from this statistical model; it allows from the tellend parts of its curves. Last but not the least is the simplicity of this function, i.e., easily understood without much complex mathematical expressions. Additionally this probability function had been used in various research experiments regarding land and environmental degradation (Sasikala et al. 2001; Bahrami et al. 2005; Mashayekhan and Honardoust 2011).

There are two natural parameters namely NDVI and soil depth that are inversely related to desertification. Thus for these parameters, the risk classes are:

- High: transitional values in between class 1 and class 2

- Moderate: transitional values in between class 2 and class 3 
- Low: values more than $\mu+2 \sigma$ of the last class

On the other hand, slope is directly related to desertification. Thus the risk classes are:

- Low: transitional values in between class 1 and class 2

- Moderate: transitional values in between class 2 and class 3

- High: values more than $\mu+2 \sigma$ of the last class

The risk classes of soil texture were derived considering the combined effects of sand, silt and clay percentage in the soil. First the risk values were identified for individual constituents, using fuzzy membership analysis. Then their combined effects were realized using fuzzy rule-based interference system based on expert knowledge.

In case of soil $\mathrm{pH}$, the risk classes were derived separately, as both the low and high values of $\mathrm{pH}$ are favourable for soil infertility, hence desertification.

Three different indices were generated, namely Terrain index (TI), Vegetation index (NDVI) and Soil index (SI). These indices were defined from the severity values of individual parameters. First two indices were eventually the severity values of slope and NDVI respectively. Soil index was derived integrating the severity values of soil depth, $\mathrm{pH}$ and texture (section 5.2).

In the final stage, for each natural parameter, the risk values were obtained and one single Desertification Risk index (DRI) was derived integrating individual natural parameters' severity following the fuzzy rule-based interference system. Interference rules were defined through IF-THEN clause. The details of these rules are given in section 5.4.

The most important step in the fuzzy system is the process of IF-THEN logic. It is quite

Table 2. Specifications of three classes of slope.

\begin{tabular}{lll}
\hline $\begin{array}{c}\text { Class } \\
\text { name }\end{array}$ & \multicolumn{1}{c}{ Range } & $\begin{array}{c}\text { Slope values } \\
\text { in degree }\end{array}$ \\
\hline 1 & $x \leq \mu-\sigma$ & $x \leq 0.02$ \\
2 & $\mu-\sigma<x \leq \mu+\sigma$ & $0.02<x \leq 1.12$ \\
3 & $x>\mu+\sigma$ & $x>1.12$ \\
\hline
\end{tabular}

important to be able to determine which input would produce the largest output with the smallest incremental change (Bardossy and Duckstein 1995; Mukaidono 2001).

The severity of aridity index was assumed as to be moderate. Other individual parameter indices are of four values depending upon their severity code. The severity code has been given as ' 0 ' for no risk, ' 1 ' for low, '2' for moderate and ' 3 ' for high risk.

\section{Observations and analysis}

The analysis was carried out for five natural parameters namely slope, soil depth, soil $\mathrm{pH}$, soil texture and NDVI following the method mentioned before. Detailed analysis and observations are given below.

\subsection{Terrain index; slope}

For terrain analysis, slope was considered. Slope is positively related to land degradation. Slope intervenes in erosion in terms of its form, gradient, length and position. Estimating the influence of the concavity, convexity, regularity or warp of a slope is a very delicate procedure. The steeper the slope, the greater the erosion, as a result of the increased velocity (swiftness) of water-flow and wind flow in the downward direction of the slope (Wischmeier 1974). Slope was derived by inverse distance weighted method (IDW) (Yang and Hodler 2000) method. The spot height values ranges between 200 and $450 \mathrm{~m}$ approximately giving a range of slope from about 0.0004-9.26 degree with a mean value $\mu=0.57$ degree and standard deviation $\sigma=0.55$ degree. There are no values less than $\mu-2 \sigma$, i.e., 0.014. Thus three classes are shown in table 2. For each individual classes the membership has been calculated following the normal probability density function, and accordingly the risk has been derived (table 3 ).

The graph of normal density function of class 2 shows one interesting thing which might be very significant in risk assessment (figure 3 ). This class ranges from 0.15 to 1.12 (table 3 ). In this class the values more than $0.7(\mu+\sigma$ of class 2$)$ are not only belonging to class 2 but some part of it also

Table 3. Statistics of slope classes for membership analysis to find out risk categories.

\begin{tabular}{|c|c|c|c|c|c|c|c|c|}
\hline $\begin{array}{l}\text { Class } \\
\text { name }\end{array}$ & Range & $\mu$ & $\sigma$ & $\mu-\sigma$ & $\mu+\sigma$ & $\begin{array}{l}\text { Risk category } \\
\text { range }\end{array}$ & Risk name & $\begin{array}{l}\text { Risk } \\
\text { code }\end{array}$ \\
\hline 1 & $0.0004-0.013$ & 0.007 & 0.004 & 0.003 & 0.012 & 0.012 to 0.16 & High & 3 \\
\hline 2 & $0.15-1.12$ & 0.43 & 0.27 & 0.16 & 0.7 & 0.7 to 0.93 & Moderate & 2 \\
\hline 3 & $1.12-9.26$ & 0.74 & 0.8 & 0.93 & 2.55 & $>2.55$ & Low & 1 \\
\hline \multicolumn{7}{|c|}{ All other recorded values of soil depth } & No risk & 0 \\
\hline
\end{tabular}



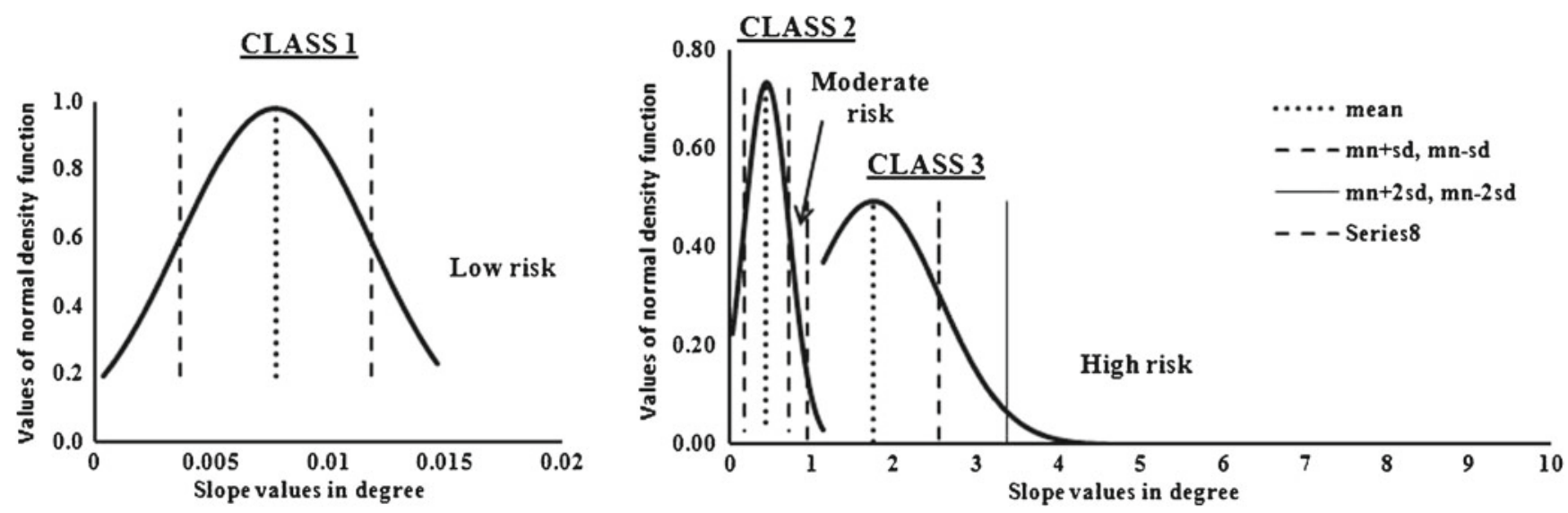

Figure 3. Normal density function of individual slope classes indicating different risk categories.

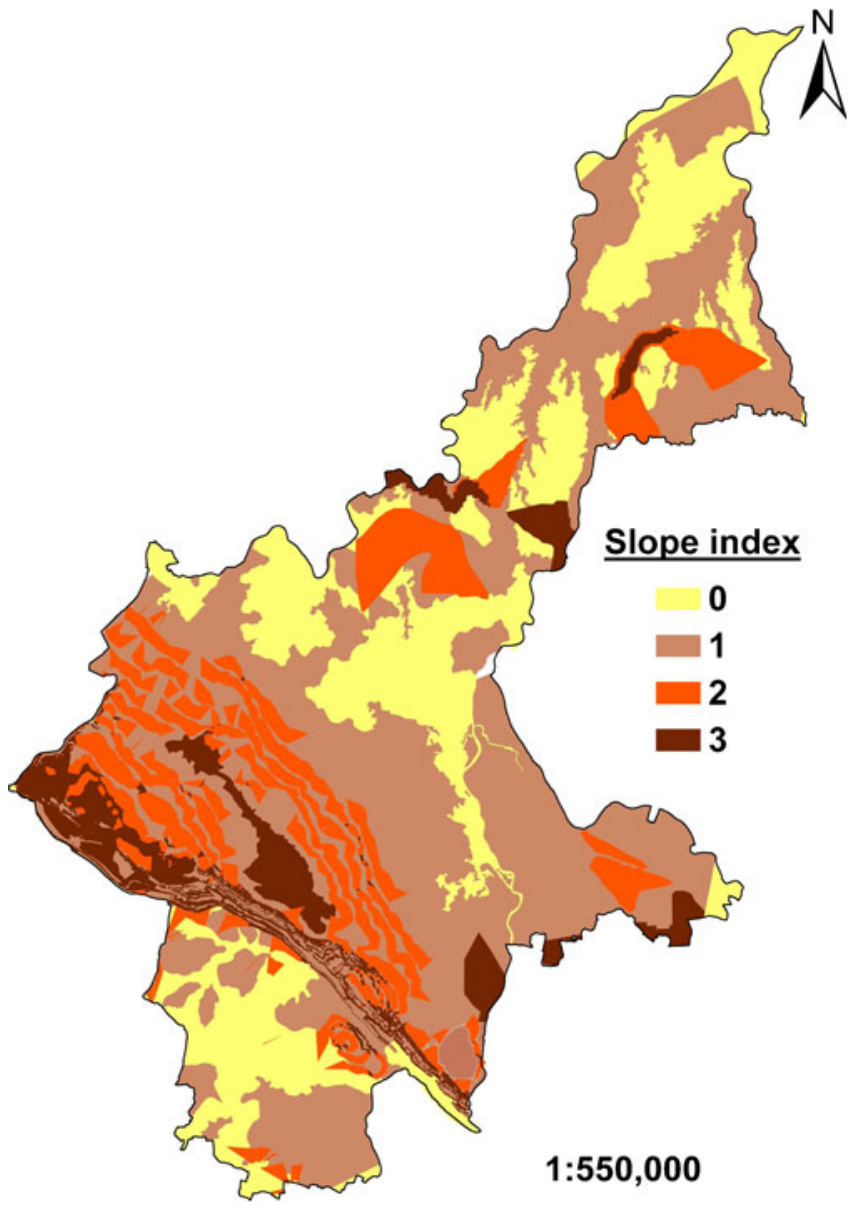

Figure 4. Terrain index map showing areas under different severity of slope risk.

intruded into the next class, i.e., class 3. These values have a tendency to increase, specifically the values more than $0.93(\mu-\sigma$ of class 3$)$. Thus the areas with these values of slope could be identified for implementing preventive methods to check the increament in slope. In addition, the values more than $2.55(\mu+\sigma$ of class 3$)$ are at very high
Table 4. Specifications of three classes of soil depth.

\begin{tabular}{lll}
\hline $\begin{array}{l}\text { Class } \\
\text { name }\end{array}$ & \multicolumn{1}{c}{ Range } & \multicolumn{1}{c}{$\begin{array}{c}\text { Values } \\
\text { in meter }\end{array}$} \\
\hline 1 & $x \leq \mu-\sigma$ & $x \leq 9.71$ \\
2 & $\mu-\sigma<x \leq \mu+\sigma$ & $9.71<x \leq 21.07$ \\
3 & $x>\mu+\sigma$ & $x>21.07$ \\
\hline
\end{tabular}

risk, and required attention to check the increasing tendency. Terrain index map was prepared using different severity of slope risk (figure 4).

\subsection{Soil index \\ 5.2.1 Soil depth}

The unconsolidated material immediate the surface of the earth serves as natural medium for the growing plants. Soil depth defines the root space and the volume of soil from where the plants fulfill their water and nutrient demands. A general classification of soil depth is given in table 6 (Kosmas et al. 1999). Spatial patterns in soil depth arise from complex interactions of many factors (topography, parent material, climate, biological, chemical and physical processes) (Jenny 1941; Hoover and Hursh 1943; Summerfield 1997). Spatial patterns in soil depth significantly affect soil moisture, runoff generation, and subsurface and groundwater flow (Freer et al. 2002; Stieglitz et al. 2003; McNamara et al. 2005; Gribb et al. 2009; Seyfried et al. 2009). Soil depth also provides an indication of the available water capacity, and exerts a major control on biological productivity (Gessler et al. 1995), which in turn affects evapotranspiration.

Soil formed on Tertiary and Quaternary consolidated formations usually have a restricted soil depth or the thickness of the soil above the bedrock 
Table 5. Statistics of soil-depth classes for membership analysis to find out risk categories.

\begin{tabular}{|c|c|c|c|c|c|c|c|c|}
\hline $\begin{array}{l}\text { Class } \\
\text { name }\end{array}$ & Range & $\mu$ & $\sigma$ & $\mu-\sigma$ & $\mu+\sigma$ & $\begin{array}{c}\text { Risk category } \\
\text { range }\end{array}$ & Risk name & $\begin{array}{l}\text { Risk } \\
\text { code }\end{array}$ \\
\hline 1 & $7-9.71$ & 7.59 & 0.89 & 6.7 & 8.48 & 8.48 to 10.56 & High & 3 \\
\hline 2 & $9.71-21.07$ & 13.78 & 3.31 & 10.56 & 17.20 & 17.20 to 23.07 & Moderate & 2 \\
\hline 3 & $21.07-30$ & 24.92 & 1.85 & 23.07 & 26.77 & $>26.77$ & Low & 1 \\
\hline \multicolumn{7}{|c|}{ All other recorded values of soil depth } & No risk & 0 \\
\hline
\end{tabular}

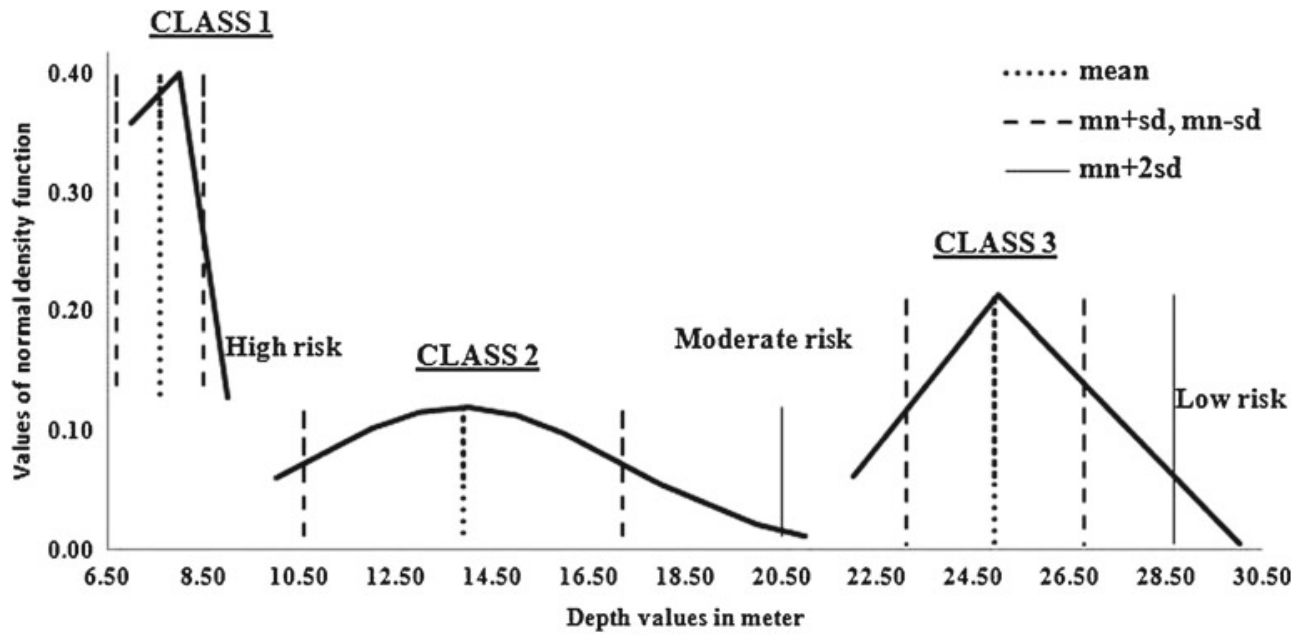

Figure 5. Normal density function of individual soil-depth classes indicating different risk categories.

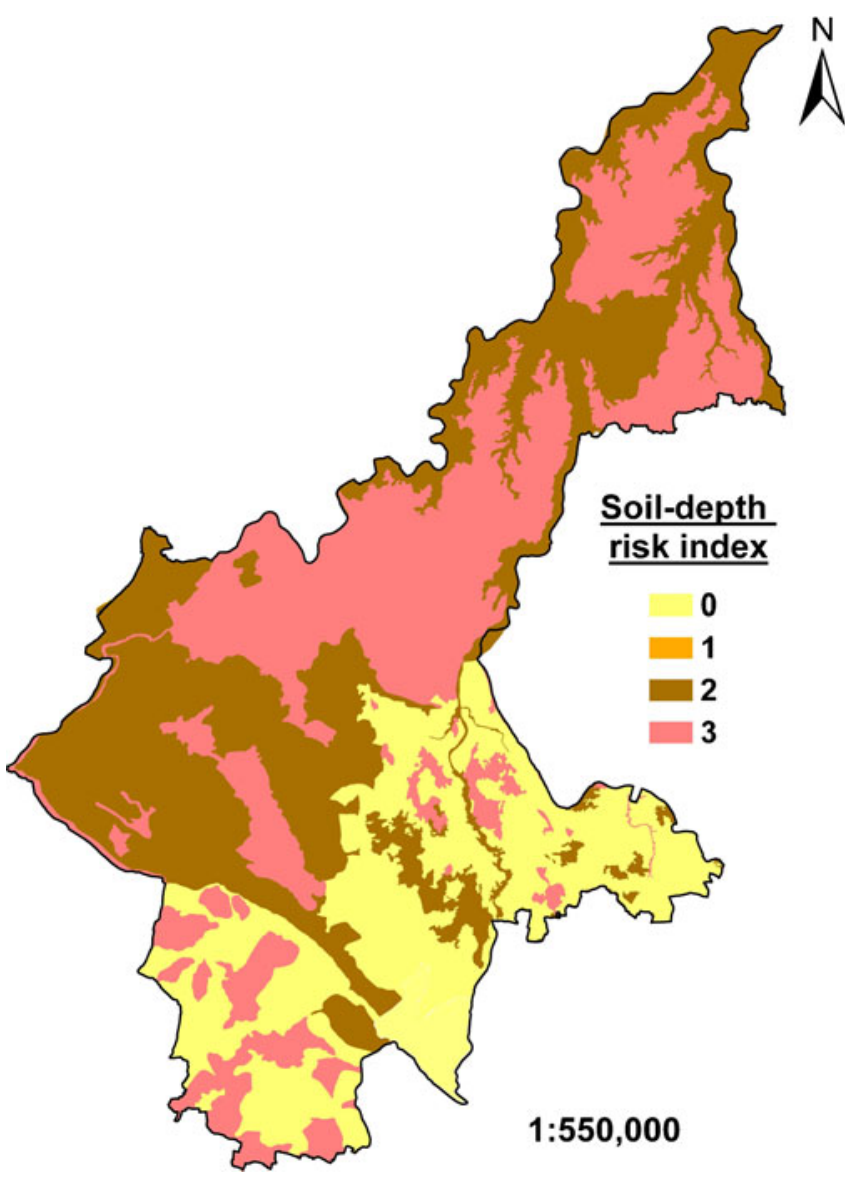

Figure 6. Soil-depth map showing areas under different severity of soil-depth risk.
Table 6. Soil reaction classification by USDA 1999.

\begin{tabular}{ll}
\hline Soil type & pH range \\
\hline Ultra acid & $<3.5$ \\
Extremely acid & $3.5-4.4$ \\
Very strongly acid & $4.5-5.0$ \\
Strongly acid & $5.1-5.5$ \\
Moderately acid & $5.5-6.0$ \\
Slightly acid & $6.1-6.5$ \\
Neutral & $6.6-7.3$ \\
Slightly alkaline & $7.4-7.8$ \\
Moderately alkaline & $7.9-8.4$ \\
Strongly alkaline & $8.5-9.0$ \\
Very strongly alkaline & $>9$ \\
\hline
\end{tabular}

Table 7. Specifications of three classes of soil-pH.

\begin{tabular}{lll}
\hline $\begin{array}{c}\text { Class } \\
\text { name }\end{array}$ & \multicolumn{1}{c}{ Range } & \multicolumn{1}{c}{$\begin{array}{c}\text { Values } \\
\text { in meter }\end{array}$} \\
\hline 1 & $x \leq \mu-\sigma$ & $x \leq 7.50$ \\
2 & $\mu-\sigma<x \leq \mu+\sigma$ & $7.50<x \leq 8.55$ \\
3 & $x>\mu+\sigma$ & $x>8.55$ \\
\hline
\end{tabular}

or the limiting subsurface layer is small reducing the rooting depth and rainfed vegetation cannot be supported under hot and dry climatic conditions leading to desertification. Soil water-storage capacity and effective rooting depth are mainly related to the soil depth (Kosmas et al. 1999). 
Table 8. Statistics of soil-pH classes for membership analysis to find out risk categories.

\begin{tabular}{|c|c|c|c|c|c|c|c|c|}
\hline $\begin{array}{l}\text { Class } \\
\text { name }\end{array}$ & Range & $\mu$ & $\sigma$ & $\mu-\sigma$ & $\mu+\sigma$ & $\begin{array}{l}\text { Risk category } \\
\text { range }\end{array}$ & Risk name & $\begin{array}{l}\text { Risk } \\
\text { code }\end{array}$ \\
\hline 1 & $6.45-7.65$ & 7.04 & 0.43 & 6.61 & 7.47 & $7.47-7.94$ & Low & 1 \\
\hline 2 & $7.65-8.25$ & 8.08 & 0.14 & 7.94 & 8.23 & $8.23-8.28$ & Moderate & 2 \\
\hline 3 & $8.25-8.70$ & 8.39 & 0.12 & 8.28 & 8.50 & $>8.50$ & High & 3 \\
\hline \multicolumn{7}{|c|}{ All other recorded values of soil $\mathrm{pH}$} & No risk & 0 \\
\hline
\end{tabular}

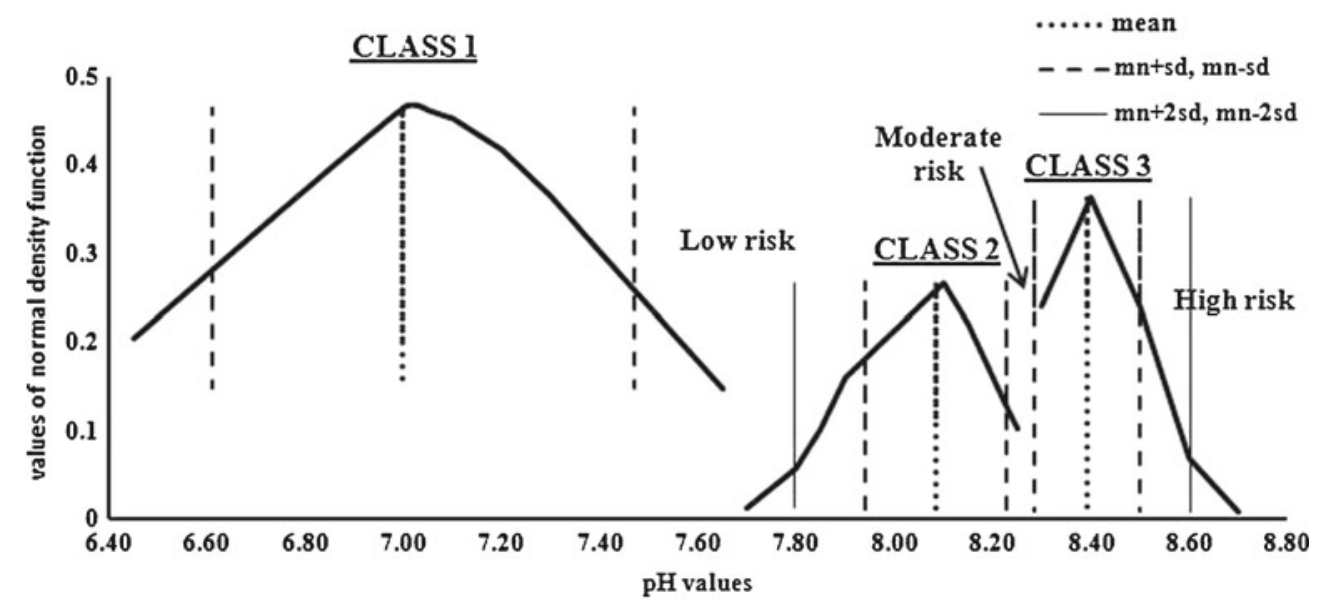

Figure 7. Normal density function of individual soil $\mathrm{pH}$ indicating different risk categories.

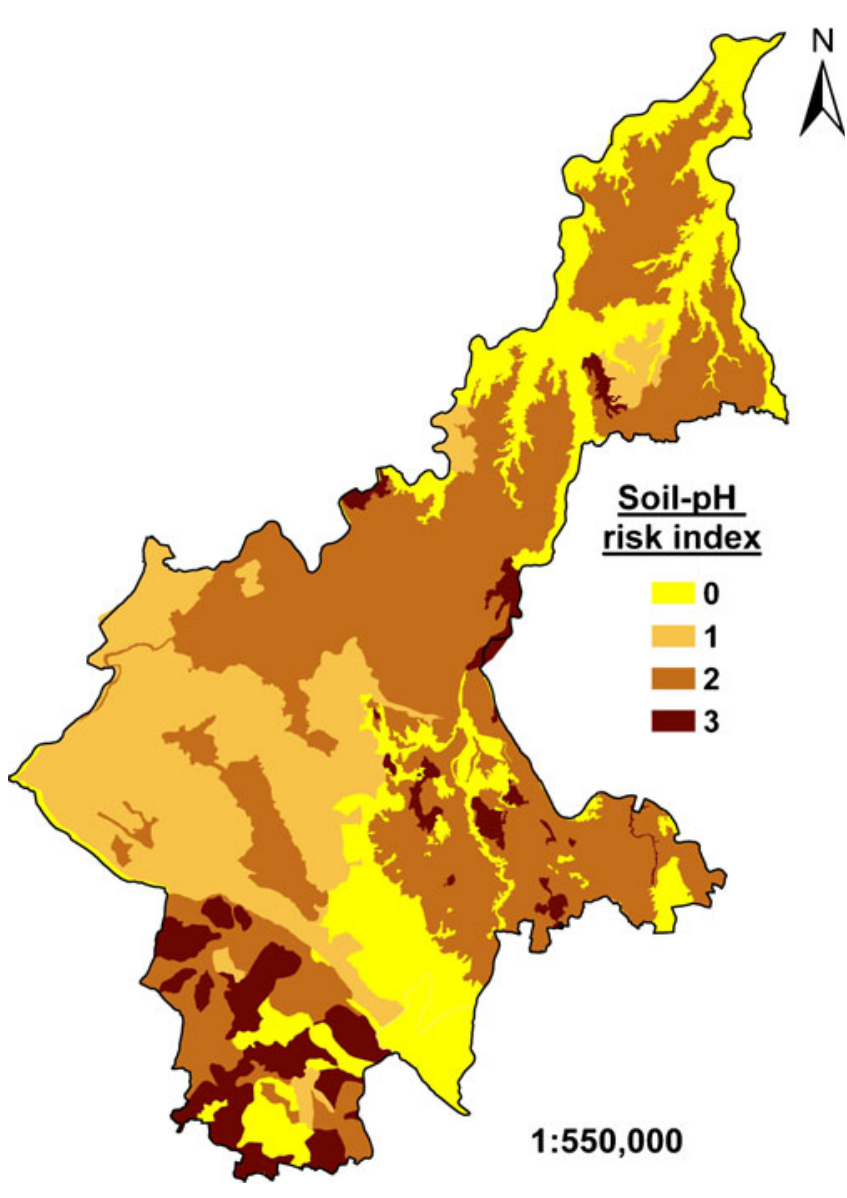

Figure 8. Soil-pH map showing areas under different severity of soil-depth risk.
Soil depth is inversely related to soil degradation. The soil having high depth shows differentiation between distinct horizontal bands, known as soil horizon, indicating a well developed mature soil. Less deep soils are easily erodable. In Kota, the depth of soil ranges between 7 and $30 \mathrm{~m}$, with $\mu=$ 15.40 and $\sigma=5.68$. The three classes are given in table 4 . The risk categories were explained in table 5 .

The interclass transitional values were identified from the normal distributions of each individual classes (figure 5). The graphs of normal density function of class 1 and class 3 show steep slope in both their sides due to less variability in data. The areas having depth of about 8.5 to $10.5 \mathrm{~m}$ are in high risk. Due to low depth the soil is susceptible to be eroded with little disturbances. On the other hand, the areas having depth of about 17 to $23 \mathrm{~m}$ are in moderate risk. In addition, the areas having depth in between $20.5(\mu+2 \sigma$ of class 2$)$ and $23 \mathrm{~m}(\mu+\sigma$ of class 3$)$ are very weakly representing class 2 but than that of class 3 . These areas might be identified to check the depth with positive measures, and thus preventing more erosion. Soil-depth map was prepared showing the severity of risks (figure 6).

\subsubsection{Soil $p H$}

Soil $\mathrm{pH}$ is a measure of the acidity or alkalinity in soils, which is commonly called soil reaction. 
Table 9. Specifications of three classes of three constituents of soil texture, i.e., sand, silt and clay percentage.

\begin{tabular}{|c|c|c|c|c|}
\hline \multirow{2}{*}{$\begin{array}{l}\text { Class } \\
\text { name }\end{array}$} & \multirow[b]{2}{*}{ Range } & \multicolumn{3}{|c|}{ Values in percentage } \\
\hline & & Sand & Silt & Clay \\
\hline 1 & $x \leq \mu-\sigma$ & $x \leq 30.30$ & $x \leq 11.44$ & $x \leq 16.87$ \\
\hline $\begin{array}{l}2 \\
3\end{array}$ & $\begin{array}{l}\mu-\sigma<x \leq \mu+\sigma \\
x>\mu+\sigma\end{array}$ & $\begin{array}{l}30.30<x \leq 67.52 \\
x>67.52\end{array}$ & $\begin{array}{l}11.44<x \leq 29.92 \\
x>29.92\end{array}$ & $\begin{array}{l}16.87<x \leq 43.09 \\
x>43.09\end{array}$ \\
\hline
\end{tabular}

Table 10. Statistics of sand, silt and clay percentage classes for membership analysis to find out risk categories.

\begin{tabular}{|c|c|c|c|c|c|c|c|c|}
\hline Class name & Range & $\mu$ & $\sigma$ & $\mu-\sigma$ & $\mu+\sigma$ & $\begin{array}{l}\text { Risk category } \\
\text { range }\end{array}$ & $\begin{array}{l}\text { Risk } \\
\text { name }\end{array}$ & $\begin{array}{l}\text { Risk } \\
\text { code }\end{array}$ \\
\hline \multicolumn{9}{|c|}{ Sand percentage } \\
\hline 1 & $11.8-28.6$ & 20.33 & 6.14 & 14.17 & 26.48 & $26.48-32.77$ & Low & 1 \\
\hline 2 & $31.7-62.24$ & 52.53 & 9.76 & 32.77 & 52.28 & $52.28-70.54$ & Moderate & 2 \\
\hline 3 & $70.4-83$ & 73.41 & 2.87 & 70.54 & 76.29 & $>76.29$ & High & 3 \\
\hline \multicolumn{9}{|c|}{ Silt percentage } \\
\hline 1 & $4.6-11.4$ & 9.17 & 1.15 & 8.12 & 10.42 & $10.42-16.77$ & High & 3 \\
\hline 2 & $13.47-19.6$ & 21.13 & 4.36 & 16.77 & 25.49 & $25.49-29.78$ & Moderate & 2 \\
\hline 3 & $731.7-60$ & 35.18 & 5.41 & 29.78 & 40.59 & $>40.59$ & Low & 1 \\
\hline \multicolumn{9}{|c|}{ Clay percentage } \\
\hline 1 & $7.6-15.3$ & 13.27 & 1.85 & 11.41 & 15.11 & $15.11-19.13$ & Low & 1 \\
\hline 2 & $19.4-43$ & 28.81 & 9.68 & 19.13 & 38.49 & $38.49-47$ & Moderate & 2 \\
\hline 3 & $44.6-57.9$ & 51.6 & 4.59 & 47 & 56.18 & $>56.18$ & High & 3 \\
\hline \multicolumn{7}{|c|}{ All other recorded values of soil texture constituents } & No risk & 0 \\
\hline
\end{tabular}

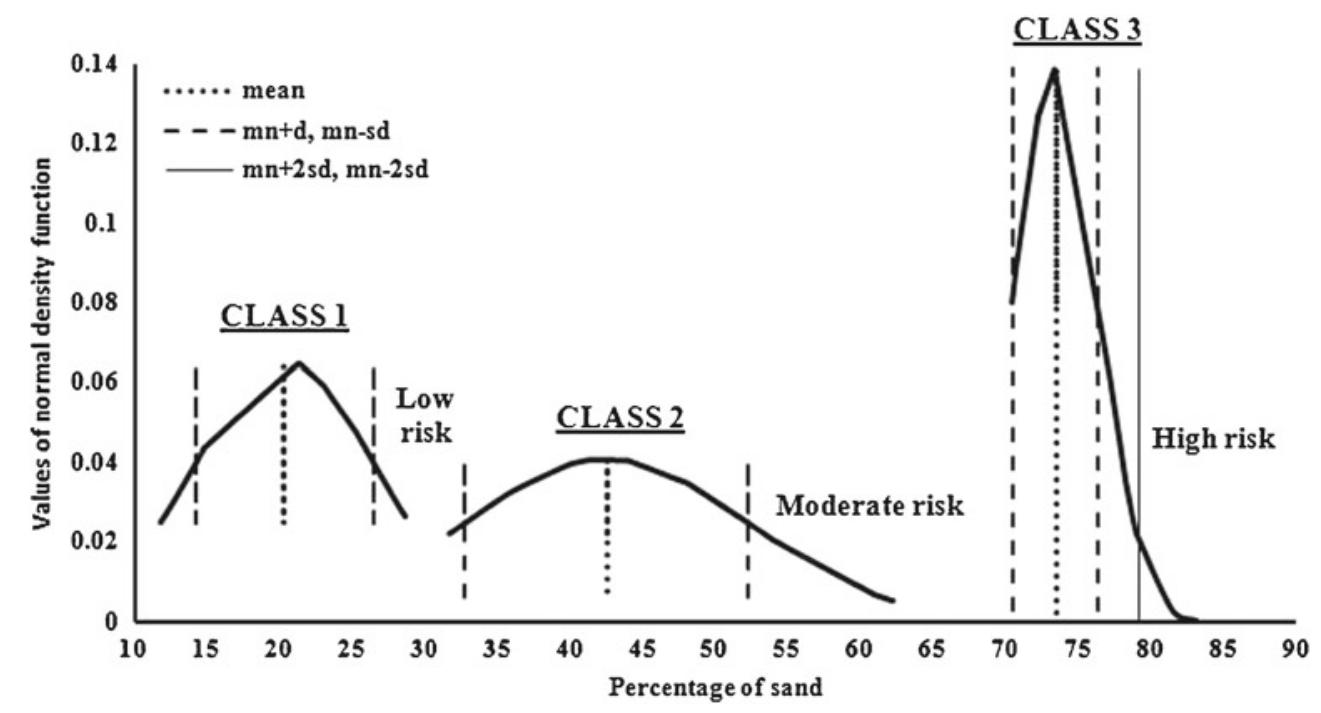

Figure 9. Normal density function of individual classes of sand percentage in soil indicating different risk categories.

$\mathrm{pH}$ is defined as the negative logarithm (base 10) of the activity of hydrogen ions $(\mathrm{H}+)$ in solution. It ranges from 0 to 14 , with 7 being neutral. A $\mathrm{pH}$ below 7 is acidic and above 7 is basic. Soil $\mathrm{pH}$ is considered as a key variable in soils as it controls many chemical processes that take place. It specifically affects plant nutrient availability by controlling the chemical forms of the nutrients. The optimum $\mathrm{pH}$ range for most plants is between 6 and
7.5, however many plants have adapted to thrive at $\mathrm{pHs}$ outside this range (Townsend 1973). Classes of soil based on $\mathrm{pH}$ factor are given in table 6 (USDA 1999). Both the higher and lower $\mathrm{pH}$ values indicate incompatibility of land for productivity hence degradation. $\mathrm{pH}$ values are classified in three successive classes, namely Low, Moderate and High, according to their deviation from mean in ascending order. It is to be noticed that, in this case, both 


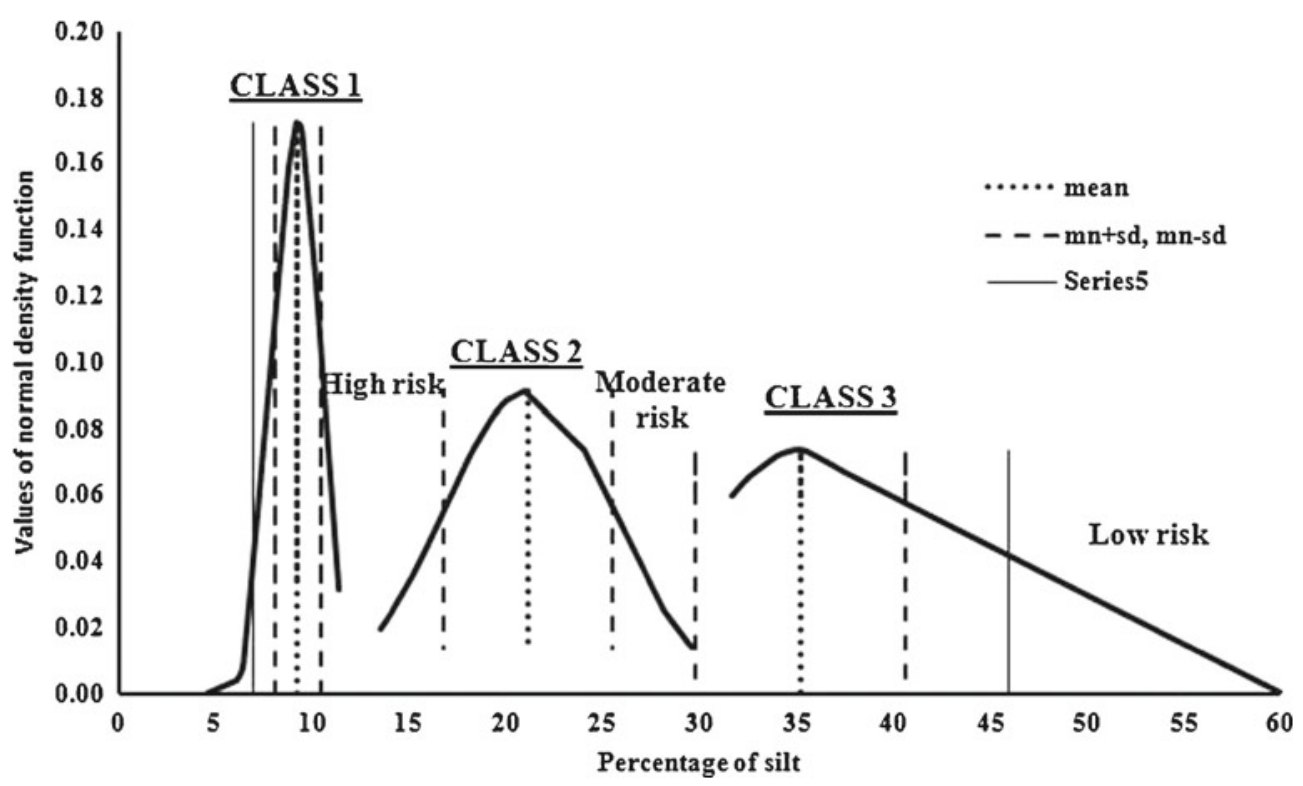

Figure 10. Normal density function of individual classes of silt percentage in soil indicating different risk categories.

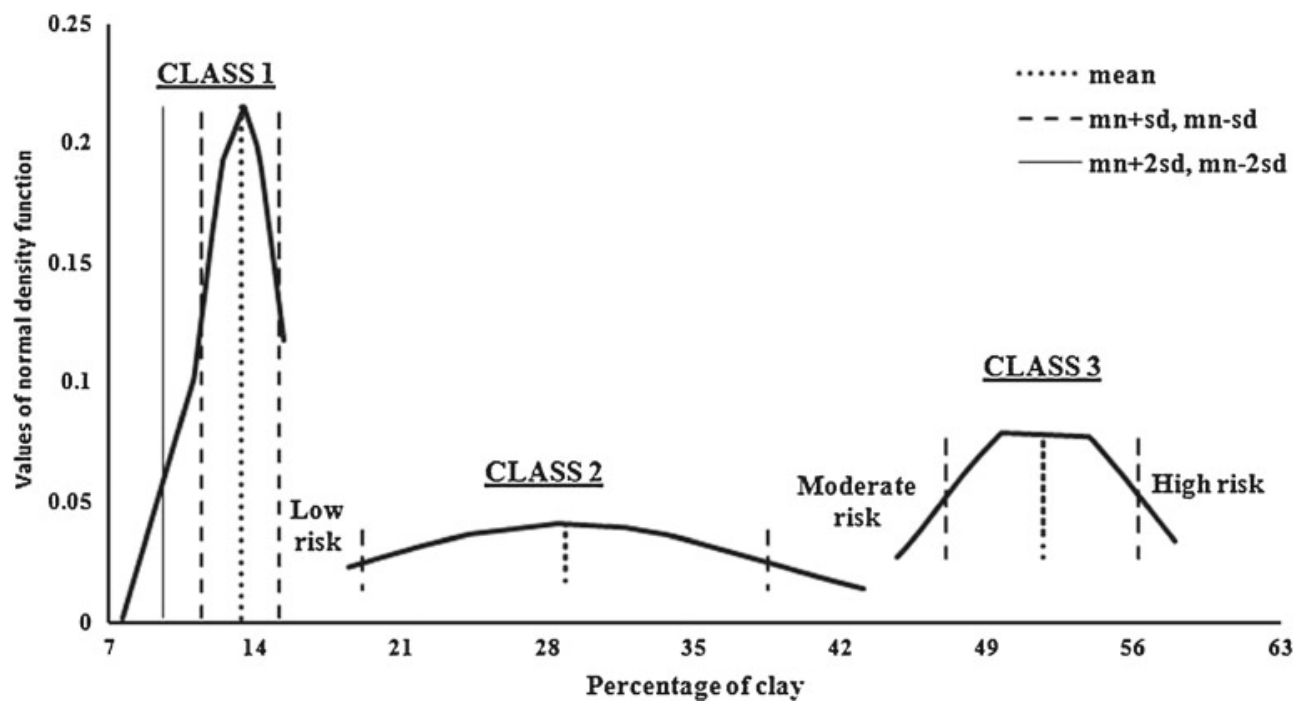

Figure 11. Normal density function of individual classes of clay percentage in soil indicating different risk categories.

the classes, low and high are vulnerable and to be considered in high risk for desertification. In Kota, the $\mathrm{pH}$ values of soil ranges between 6.45 and 8.72 , with $\mu=8.02$ and $\sigma=0.52$. $\mathrm{pH}$ values are classified in three successive classes (table 7 ). The membership analysis of three classes along with identified risk values were shown in table 8 .

The membership analysis of class 1 and class 2 (figure 7) shows a considerable number of values in between $\mu+\sigma$ of the previous class and $\mu-\sigma$ of the later class, i.e., areas with soil $\mathrm{pH}$ values from 7.4 to 7.9 , which are in low risk. Among these, the areas having $\mathrm{pH}$ values less than $7.8(\mu-2 \sigma$ of class 2) are not representing class 2 very strongly. These areas might be referred as priority areas where immediate measures can be taken to lower down the $\mathrm{pH}$ values to bring them strongly under previous class (class 1 ). On the contrary, there are some areas which are in very high risk of desertification in terms of soil $\mathrm{pH}$. These are identified from the graph of class 3, values more than 8.5 $(\mu+\sigma)$. Moreover the $\mathrm{pH}$ values of more than 8.8 $(\mu+2 \sigma$ class 3$)$ are very much susceptible to be increased, hence need immediate attention. Map was prepared showing the severity of risks of soil $\mathrm{pH}$ values (figure 8).

\subsubsection{Soil texture}

Soil texture refers to the relative proportion of primary particles of sand, silt and clay and other 
Table 11. Different textural groups with different textural combination found in Kota district.

\begin{tabular}{rllll}
\hline Sl. no. & Sand $(\%)$ & Silt $(\%)$ & Clay $(\%)$ & Texture group \\
\hline 1 & 28.6 & 32.1 & 39.3 & Clay loam \\
2 & $31.7-36.2$ & $29.4-29.6$ & $34.2-39$ & Clay loam \\
3 & $40.2-41.4$ & $28.2-34.4$ & $24.2-31.6$ & Clay loam \\
4 & $11.8-23$ & $29.6-37.6$ & $42.4-58$ & Clayey \\
5 & $26.2-40$ & $18-32.4$ & $40-54$ & Clayey \\
6 & $40.3-44$ & $14-18$ & $40-45$ & Clayey \\
7 & $48.2-52.3$ & $13.5-32.5$ & $14-20$ & Loam \\
8 & 78.2 & 9.5 & 12.4 & Loam \\
9 & $77-79$ & $9-9.5$ & $11-13.4$ & Loamy sand \\
10 & $48-54$ & $18-24$ & $22-24$ & Sandy clay loam \\
11 & 61.4 & 10.2 & 28.4 & Sandy clay loam \\
12 & 61.8 & 19.76 & 18.4 & Sandy clay loam \\
13 & $62.3-70.4$ & $9.4-16.2$ & $20-21.5$ & Sandy clay loam \\
14 & 61 & 19.4 & 19.7 & Sandy loam \\
15 & $70.7-73.3$ & $8.8-15.2$ & $12.3-19.1$ & Sandy loam \\
16 & $78.7-83$ & $4.6-6.1$ & $11-19$ & Sandy loam \\
17 & 25.2 & 20.9 & 33.3 & Silt loam \\
18 & 32.4 & 60 & 7.6 & Silt loam \\
\hline
\end{tabular}

Table 12. Interference rule to derive different risk categories in terms of different textural combinations.

\begin{tabular}{rllll}
\hline Sl. no. & Sand (\%) & \multicolumn{1}{c}{ Silt (\%) } & Clay (\%) & $\begin{array}{c}\text { Combined risk } \\
\text { category }\end{array}$ \\
\hline 1 & Low (1) & Low (1) & Moderate (2) & Low (1) \\
2 & Moderate (2) & Moderate (2) & No risk & Moderate (2) \\
3 & No risk & Moderate (2) & No risk & Moderate (2) \\
4 & No risk & No risk & High (3) & High (3) \\
5 & Low (1) & Moderate (2) & Moderate (2) & Moderate (2) \\
6 & No risk & No risk & Moderate (2) & Moderate (2) \\
7 & No risk & Low (1) & Low (1) & Low (1) \\
8 & High (3) & No risk & No risk & High (3) \\
9 & High (3) & No risk & No risk & High (3) \\
10 & Moderate (2) & No risk & No risk & Moderate (2) \\
11 & Moderate (2) & No risk & No risk & Moderate (2) \\
12 & Moderate (2) & No risk & Low (1) & Moderate (2) \\
13 & Moderate (2) & Low (1) & No risk & Moderate (2) \\
14 & Moderate (2) & No risk & Low (1) & Moderate (2) \\
15 & Moderate (2) & Low (1) & Low (1) & Low (1) \\
16 & High (3) & Low (1) & Low (1) & High (3) \\
17 & No risk & No risk & No risk & No risk \\
18 & Low (1) & No risk & No risk & Low (1) \\
\hline
\end{tabular}

skelital materials of soil body (Lal 1979). The combined portions of sand, silt, and clay in a soil determine its textural classification. Sand particles range in size from 0.05 to $2.0 \mathrm{~mm}$, silt ranges from 0.002 to $0.05 \mathrm{~mm}$, and the clay fraction is made up of particles less than $0.002 \mathrm{~mm}$ in diameter. Gravel or rocks greater than $2 \mathrm{~mm}$ in diameter are not considered when determining texture. Once the sand, silt, and clay percentages of a soil are known, the textural class can be read from the textural triangle (Berry et al. 2007). Soil texture profoundly affects soil drainage, water holding capacity, soil temperature, soil erosion as well as fertility and productivity (Kosmas et al. 1999; Fitzpatrick 2002; Berry et al. 2007).

The ranges of sand, silt and clay percentage along with their classes are given in table 9. Membership analysis was carried out for each classes of 
Table 13. Interference rule to derive soil index in terms of different soil-depth, soil-pH and soil textural combinations.

\begin{tabular}{ccccc}
\hline Sl. no. & $\begin{array}{c}\text { Soil depth } \\
\text { risk index }\end{array}$ & $\begin{array}{c}\text { Soil pH } \\
\text { risk index }\end{array}$ & $\begin{array}{c}\text { Soil texture } \\
\text { risk index }\end{array}$ & $\begin{array}{c}\text { Soil index } \\
(\text { SI })\end{array}$ \\
\hline 1 & 0 & 0 & 0 & 0 \\
2 & 0 & 0 & 2 & 2 \\
3 & 0 & 0 & 3 & 3 \\
4 & 0 & 1 & 2 & 2 \\
5 & 0 & 1 & 3 & 3 \\
6 & 0 & 2 & 2 & 2 \\
7 & 0 & 3 & 0 & 3 \\
8 & 0 & 3 & 3 & 3 \\
9 & 2 & 2 & 2 & 2 \\
10 & 2 & 3 & 0 & 3 \\
11 & 3 & 0 & 0 & 3 \\
12 & 3 & 0 & 2 & 3 \\
13 & 3 & 2 & 3 & 3 \\
\hline
\end{tabular}

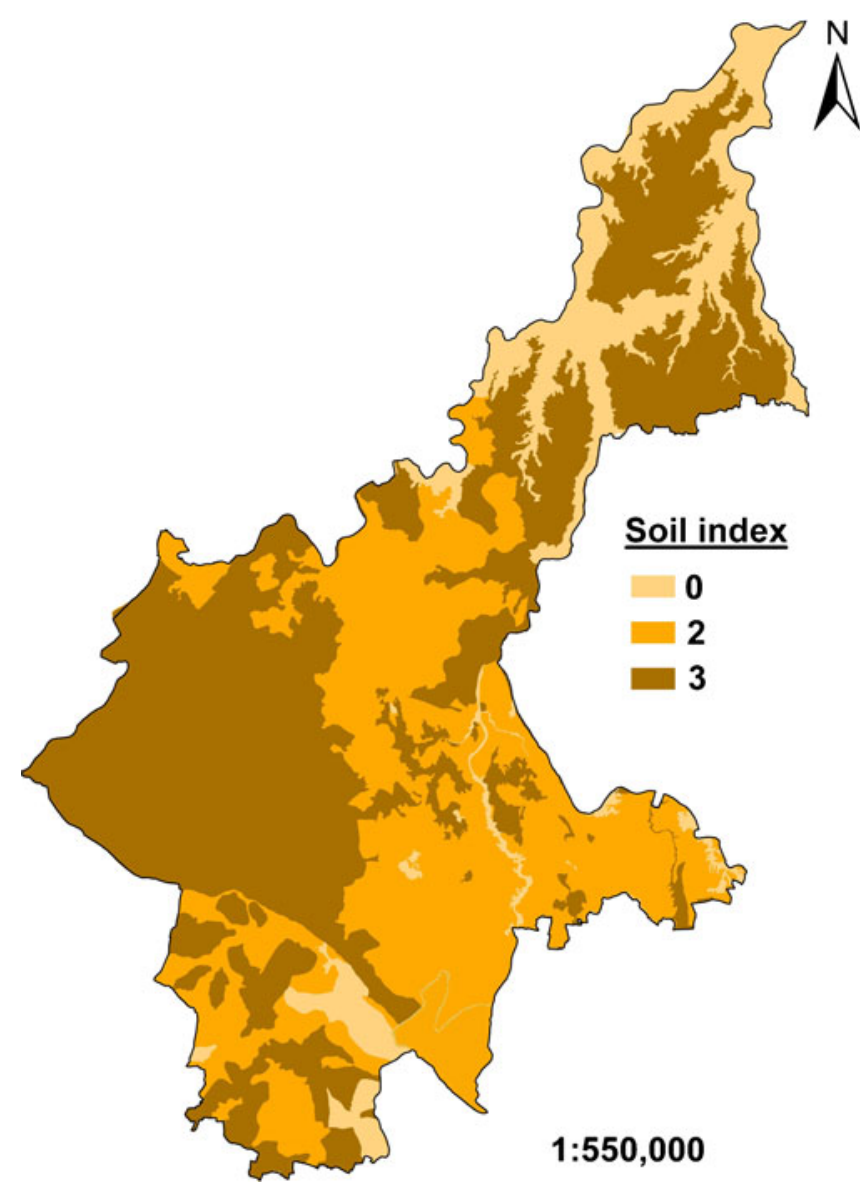

Figure 12. Soil index map showing areas under different severity of soil risk, based on risk-severities of soil depth, soil $\mathrm{pH}$ and soil texture.

all three different constituents to derive the risk categories, as explained in table 10. Risk categories were identified from the normal density function of each class of individual parameters, namely sand, silt and clay as shown in figures 9, 10 and 11,
Table 14. Specifications of three classes of NDVI.

\begin{tabular}{lll}
\hline $\begin{array}{l}\text { Class } \\
\text { name }\end{array}$ & \multicolumn{1}{c}{ Range } & NDVI values \\
\hline 1 & $x \leq \mu-\sigma$ & $x \leq 0.14$ \\
2 & $\mu-\sigma<x \leq \mu+\sigma$ & $0.14<x \leq 0.50$ \\
3 & $x>\mu+\sigma$ & $x>0.50$ \\
\hline
\end{tabular}

respectively. There are total 18 soil-textural groups with 18 different textural combinations (table 11) in Kota district. These combinations were compared with table 10 to derive the risk categories. Combined risk categories were derived using fuzzy interference rule based on expert knowledge (table 12).

Soil index was derived by combining soil depth, soil $\mathrm{pH}$ and soil texture severity using fuzzy rulebased interference system. In all, 13 unique combinations were found (table 13). Figure 12 shows areas under different risks of soil texture.

\subsection{Vegetation index; NDVI}

The most important single factor in the protection of soil fertility, hence productivity, is vegetation. Areas affected by desertification processes lose progressively their level of biological quality and productivity. Destruction of vegetation, most often by human activities accelerates soil degradation, hence coupling with other responsible factors, leading desertification.

The fundamental behind NDVI is that the internal mesophyll structure of healthy green leaves strongly reflects NIR radiation and leaf chlorophyll and other pigments absorb a large proportion of the red VIS radiation. Therefore, higher photosynthetic activity will result in lower reflectance in the red channel and higher reflectance in the near infrared channel. This signature is unique to green plants (figure 9). This becomes reverse in case of unhealthy or water stressed vegetation. Thus vegetation vigour can be portrayed in NDVI which can be obtained from following the formula NDVI $=(\mathrm{IR}-\mathrm{R}) /(\mathrm{IR}+\mathrm{R})$, where, $\mathrm{IR}$ and $\mathrm{R}$ are the reflectance value of pixels in infra-red and red band, respectively (Tucker 1979; Jackson et al. 1983; Tucker et al. 1991). NDVI values range between -1 and +1 , representing different chlorophyll content, indicating the health status of vegetation. Generally, healthy vegetation absorbs most of the visible light that falls on it and reflects a large portion of the near-infrared light. Unhealthy or sparse vegetation reflects more visible light and less near-infrared light. Bare soils on the other hand reflect moderately in both red and infrared portion of the electromagnetic spectrum (Holme et al. 1987). 
Table 15. Statistics of NDVI classes for membership analysis to find out risk categories.

\begin{tabular}{|c|c|c|c|c|c|c|c|c|}
\hline $\begin{array}{l}\text { Class } \\
\text { name }\end{array}$ & Range & $\mu$ & $\sigma$ & $\mu-\sigma$ & $\mu+\sigma$ & $\begin{array}{c}\text { Risk category } \\
\text { range }\end{array}$ & $\begin{array}{c}\text { Risk } \\
\text { name }\end{array}$ & $\begin{array}{l}\text { Risk } \\
\text { code }\end{array}$ \\
\hline 1 & $0.003-0.13$ & 0.07 & 0.04 & 0.03 & 0.12 & $0.12-0.21$ & High & 3 \\
\hline 2 & $0.14-0.5$ & 0.32 & 0.12 & 0.21 & 0.43 & $0.43-0.53$ & Moderate & 2 \\
\hline 3 & $0.5-0.67$ & 0.57 & 0.04 & 0.53 & 0.62 & $>0.62$ & Low & 1 \\
\hline \multicolumn{7}{|c|}{ All other recorded values of soil depth } & No risk & 0 \\
\hline
\end{tabular}

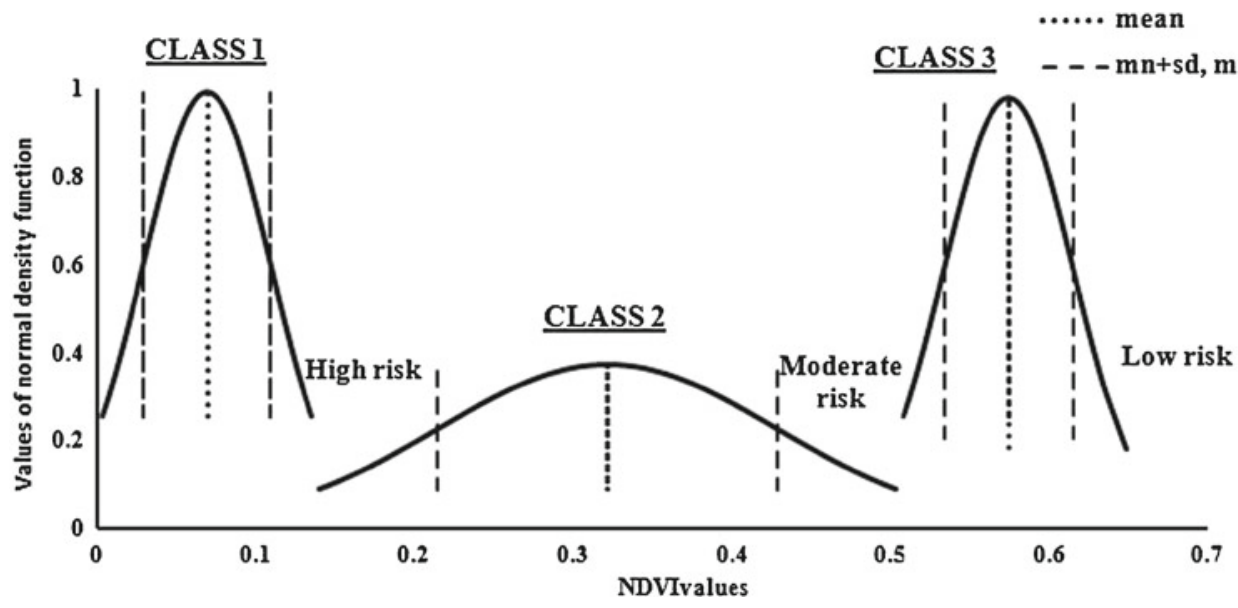

Figure 13. Normal density function of individual NDVI classes indicating different risk categories.

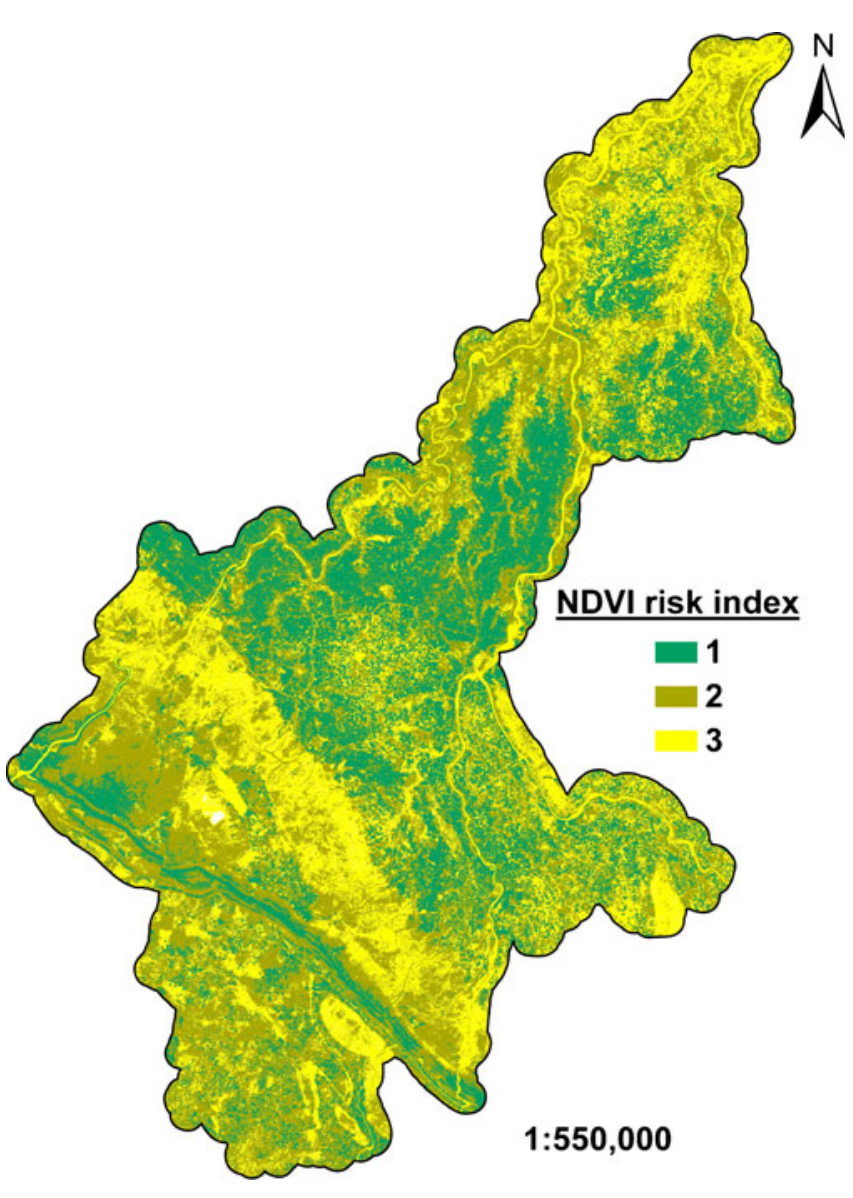

Figure 14. NDVI map showing areas under different severity of NDVI risk.
From the whole image of Kota district, only the area covered by forest and scrubland were taken under consideration to analyze the NDVI of natural vegetation. The NDVI values of agricultural areas and other land uses were considered as no risk and coded as ' 0 '. The DN value images were converted into spectral radiance image, and further into apparent reflectance image (Lillesand and Kiefer 2000). NDVI values range from about 0.003 to 0.65 with 0.32 mean and 0.18 standard deviation, and are classified into three classes (table 14), $x$ being a single variable. Table 15 shows the risk categorization. Membership analysis of NDVI values are shown in figure 13 . Negative NDVI values were omitted before classification and analysis, as these are representative of mainly water bodies. NDVI map was prepared displaying areas under different risk of NDVI (figure 14).

\subsection{Desertification risk index; DRI}

This stage involved the integration of all three natural parameter indices, namely soil index, terrain index and NDVI, using fuzzy rule-based interference system. The rules are as follows:

- If all indices are 0, then DRI is 0 .

- If any one of the indices is 1 , and others are less than or equal to 1 , then DRI is 1 .

- If any one of the indices is 2 , and others are less than or equal to 2 , then DRI is 2 . 
Table 16. Interference rule to derive different risk categories in terms of different textural combinations.

\begin{tabular}{|c|c|c|c|c|}
\hline Sl. no. & $\begin{array}{l}\text { Terrain } \\
\text { index }\end{array}$ & $\begin{array}{l}\text { Soil } \\
\text { index }\end{array}$ & $\begin{array}{c}\text { Vegetation } \\
\text { index }\end{array}$ & $\begin{array}{l}\text { Desertification } \\
\text { risk index } \\
(\mathrm{DRI})\end{array}$ \\
\hline 1 & 0 & 0 & 1 & 1 \\
\hline 2 & 0 & 1 & 0 & 1 \\
\hline 3 & 0 & 1 & 1 & 1 \\
\hline 4 & 1 & 0 & 0 & 1 \\
\hline 5 & 1 & 0 & 1 & 1 \\
\hline 6 & 1 & 1 & 0 & 1 \\
\hline 7 & 1 & 1 & 1 & 1 \\
\hline 8 & 0 & 0 & 2 & 2 \\
\hline 9 & 0 & 1 & 2 & 2 \\
\hline 10 & 0 & 2 & 0 & 2 \\
\hline 11 & 0 & 2 & 2 & 2 \\
\hline 12 & 1 & 2 & 0 & 2 \\
\hline 13 & 2 & 0 & 0 & 2 \\
\hline 14 & 2 & 1 & 0 & 2 \\
\hline 15 & 2 & 2 & 0 & 2 \\
\hline 16 & 2 & 1 & 1 & 2 \\
\hline 17 & 2 & 1 & 2 & 2 \\
\hline 18 & 2 & 2 & 1 & 2 \\
\hline 19 & 2 & 2 & 2 & 2 \\
\hline 20 & 0 & 0 & 3 & 3 \\
\hline 21 & 0 & 1 & 3 & 3 \\
\hline 22 & 0 & 2 & 3 & 3 \\
\hline 23 & 0 & 3 & 0 & 3 \\
\hline 24 & 0 & 3 & 1 & 3 \\
\hline 25 & 0 & 3 & 2 & 3 \\
\hline 26 & 1 & 3 & 0 & 3 \\
\hline 27 & 2 & 1 & 3 & 3 \\
\hline 28 & 2 & 2 & 3 & 3 \\
\hline 29 & 2 & 3 & 0 & 3 \\
\hline 30 & 2 & 3 & 1 & 3 \\
\hline 31 & 3 & 0 & 0 & 3 \\
\hline 32 & 3 & 0 & 2 & 3 \\
\hline 33 & 3 & 1 & 0 & 3 \\
\hline 34 & 3 & 1 & 1 & 3 \\
\hline 35 & 3 & 1 & 2 & 3 \\
\hline 36 & 3 & 1 & 3 & 3 \\
\hline 37 & 3 & 2 & 0 & 3 \\
\hline 38 & 3 & 2 & 1 & 3 \\
\hline 39 & 3 & 2 & 2 & 3 \\
\hline 40 & 3 & 2 & 3 & 3 \\
\hline 41 & 3 & 3 & 0 & 3 \\
\hline 42 & 3 & 3 & 1 & 3 \\
\hline 43 & 3 & 3 & 2 & 3 \\
\hline
\end{tabular}

- If any one of the indices is 3, and others are less than or equal to 3 , then DRI is 3 .

In the study area, 43 unique combinations were found to derive the final desertification risk indices (table 16). Accordingly overall desertification risk index map was prepared (figure 15).

\section{DESERTIFICATION RISK INDEX MAP \\ BASED ON \\ TERRAIN INDEX, SOIL INDEX AND NDVI}

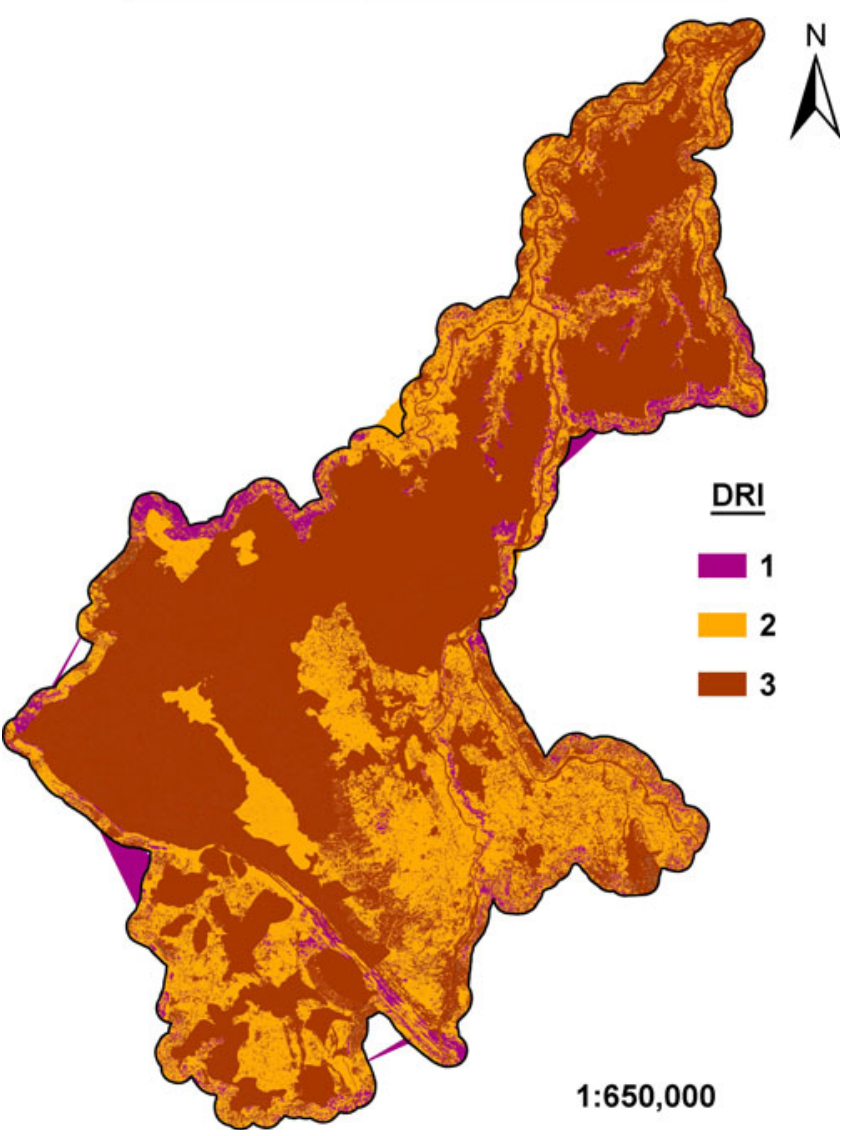

Figure 15. Desertification risk index map of study area, showing areas under different severity of desertification risk.

\section{Results and discussion}

The above observations, as inferred from the normal density functions of individual classes of individual parameters, were portrayed spatially in GIS environment to know the areas under risk of desertification with their severity.

The interpretation reveals that the southern part of Kota, particularly, Ladpura and Sangod tahsil, are under moderate to high risk in terms of individual indices (figures 4, 6, 8, 12 and 14) as well as overall desertification risk index (figure 15). In this area, the topography is prevailed by the residual mountain ranges of Aravalli with a height ranging from 350 to $450 \mathrm{~m}$ with a slope range of 0.97 to 2.5 degree. The total range of Aravalli is under moderate to high risk of degradation in terms of slope (figure 4). This area is under reserved forest, and once covered by dense forest as shown in toposheet. At present, as all the vegetation cover was removed by human intervention, the land surface is totally exposed to weather. Thus moderate to high slope coupled with surface exposure 

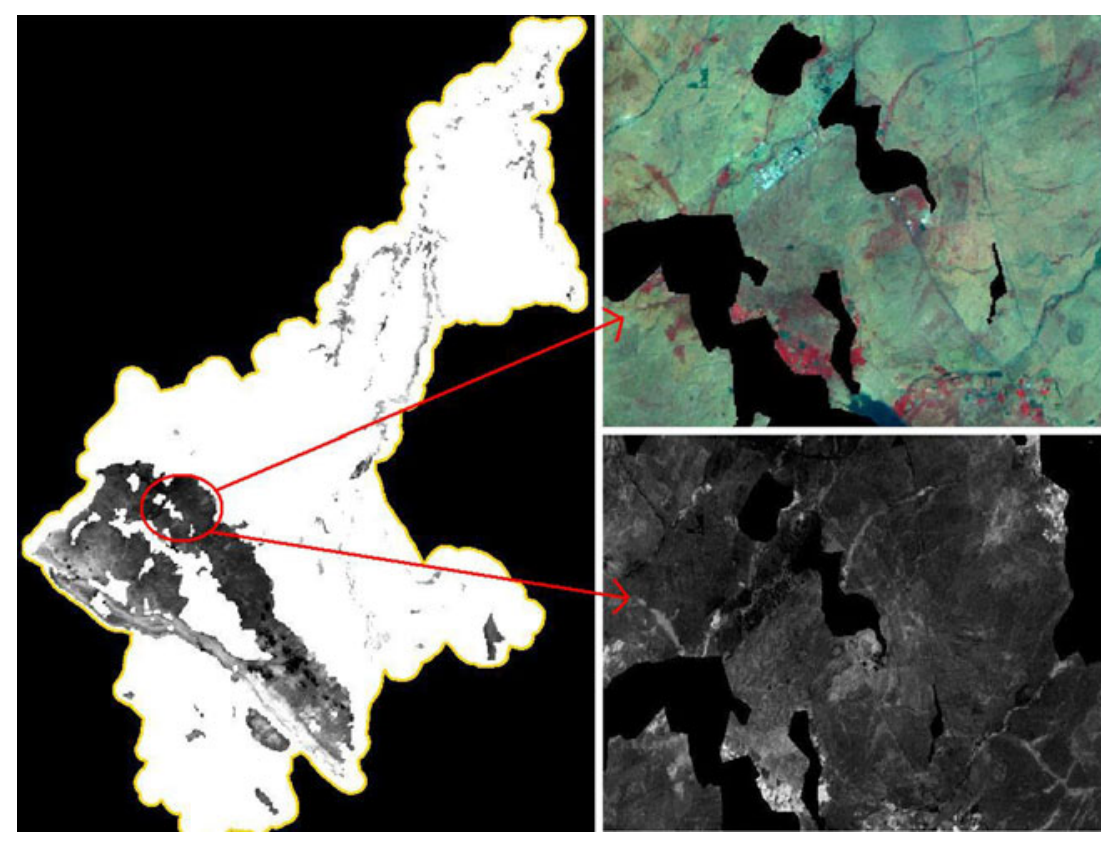

Figure 16. Certain areas over the Aravalli ridges exhibiting negative NDVI, FCC image, IRS P6, LISS III, October 2001.

due to deforestation, accelerates the soil erosion specifically by rain splash and sheet erosion. Mostly all the soil layer has been eroded by vigorous continuous erosion process through surface runoff resulting in exposing the underlying parent rock. Consequently, the area is exhibiting negative NDVI (figure 16).

The upper and middle parts of the district, in Pipalda and Digod taluk, are also in moderate to high risk of degradation (figure 12) due to high soil index resulting from low soil depth and high soil $\mathrm{pH}$ (figures 4,6 ). Soil is getting eroded because of severe gully erosion of rivers Chambal and Kalisindh. In addition, here the soil is extremely alkaline with the $\mathrm{pH}$ value of 7.9 to 8.3 , because of water-logging and soil characteristics. In the suburban areas of Rajpura, Kadihera, Galana, Balapura, Bhagwanpura, Anandkhera, etc., the pH value ranges between 7.9 and 8.2 , may be due to soil type and densely populated area with high urban activities. The areas in and around the Kota city, near the lake region namely Kishor Sagar and Sur Sagar, and in the west of Kota barrage are also under moderate to high risk. Soil is extremely alkaline with the $\mathrm{pH}$ value of 7.9 to 8.3 , because of water-logging with the toxic sewerage material coming from nearby urban areas.

The last significant area is in southern part of the district, near Ramganjmandi-Chachat area. This area is exhibiting moderate to high risk of degradation (figure 15). Soil index is moderate to high (figure 12) due to very highly acidic soil resulting from the waste disposal of Kota-stone mining. NDVI is also showing moderate high risk (figure 14). Rapid urbanization and mining activity not only causes the deforestation but also the deterioration in the health of vegetation (Dasgupta et al. 2012).

\section{Conclusions and future scope}

The paper reveals that the fuzzy membership approach along and geoinformatics technique permit us to have a detailed analysis of continuous natural factors observed from remotely sensed data as well as other ancillary data both individually and in combination. Assessing the risk of desertification by integrating all effective factors is also possible and reasonable by this model.

The normal probability density function is suitable for membership analysis. The membership functions allow making out the areas representing the transitional zone in between two successive classes. Thus the model identifies the risk areas with their severity and facilitates appropriate decision making for combating and preventive methods.

The future scope of the study is to predict the risk severity in future and to validate the model efficiency with future status. The assessment of socio-economic parameters can also be incorporated into the study for more accurate appraisal of desertification.

\section{Acknowledgements}

Authors are thankful to Sri A S Kiran Kumar, Director and Dr J S Parihar, Dy Director, Dr Ajai, GD, MPSG, EPSA, Space Applications Centre, 
Ahmedabad for their support and encouragement. The authors thank the two anonymous reviewers who provided thoughtful review comments that significantly improved the paper. The authors are grateful to JESS Journal for the support to develop this document.

\section{References}

Bahrami H A, Vaghei H G, Vaghei B G, Tahmasbipour N and Taliey-Tabari F 2005 A new method for determining the soil erodibility factor based on fuzzy systems; J. Agri. Sci. Technol. 7 115-123.

Bardossy A and Duckstein L 1995 Fuzzy Rule-based Modeling with Application to Geophysical, Biologocal and Engineering Systems (Boca Raton: CRC Press), 221p.

Berry Wayne, Ketterings Quirine, Antes Steve, Page Steve, Jonathan Russell-Anelli, Rao Renuka and Steve DeGloria 2007 Cornwell University Agronomy Fact Sheet Series 29, Soil Texture Department of Crop and Soil Sciences, College of Agriculture and Life Sciences, 1p.

Census of India 2011 Provisional population total, Rajasthan (ed.) Singh Shubhra IAS, Joint Secretary \& Director, Census Operations, Rajasthan.

Dasgupta Arunima, Sastry K L N and Dhinwa P S 2012 Impact of mining on rural environment and economy - a case study, Kota district, Rajasthan; Int. J. Rem. Sens. Geosci. 2(3) 21-26, ISSN No: 2319-3484.

Freer J, McDonnell J J, Beven K J, Peters N E, Burns D A, Hooper R P, Aulenbach B and Kendall C 2002 The role of bedrock topography on subsurface storm flow; Water Resour. Res. 38(12) 1269p, doi: 10.1029/2001WR000872.

Fitzpatrick R W 2002 Land degradation processes; In: Regional Water and Soil Assessment for Managing Sustainable Agriculture in China and Australia (eds) McVicar T R, Li Rui, Walker J, Fitzpatrick R W and Liu Changming; ACIAR Monograph 84 119-129.

Gessler P E, Moore I D, McKenzie N J and Ryan P J 1995 Soil landscape modeling and spatial prediction of soil attributes; Int. J. Geograph. Inform. Syst. 9 421-432, doi: 10.1080/02693799508902047.

GLASOD Global Assessment of Human-induced Soil degradation 1990 International Soil Reference and Information Centre (Wageningen Netherlands) and UNEP (Nairobi, Kenya) 2004, http://lime.isric.nl/index.cfm contentid_158.

Goodman Richard 1967 Teach Yourself Statistics; 2nd edn, ELBS and The English Universities Press Ltd., London, $76 \mathrm{p}$.

Gribb M, Forkutsa I, Hansen A J, Chandler D and McNamara J P 2009 The effect of various soil hydraulic property estimates on soil moisture simulations; Vadose Zone J. 8 321-331, doi: 10.2136/vzj2008.0088.

Holme A McR, Burnside D G and Mitchell A A 1987 The development of a system for monitoring trend in range condition in the arid shrublands of Western Australia; Australian Rangeland J. 9 14-20.

Hoover M D and Hursh C R 1943 Influence of topography and soil depth on runoff from forest land; EOS Trans. $A G U 24$ 693-698.

ISFR India State Forest Report 2011 Forest Survey of India, Ministry of Environment \& Forestry, Government of India, pp. 208-215.

Jackson R D, Slater P N and Pinter P J 1983 Discrimination of growth and water stress in wheat by various vegetation indices through clear and turbid atmospheres; Rem. Sens. Environ. 15 187-208.

Jenny H 1941 Factors of soil formation: A quantitative system in pedology (New York: McGraw-Hill), 281p.

Kosmas C, Kirkby M and Geeson N 1999 Manual on: Key indicators of desertification and mapping environmentally sensitive areas to desertification EC Energy; Environ. Sustain. Develop., EUR 18882, 87p.

LADA Land Degradation Assessment in Drylands 2011 Final draft, Mapping land use systems at global and regional scales for land degradation assessment analysis 1.1 .

Lal R 1979 Physical characteristics of soils of the tropics: Determination and management in soil physical properties and crop production in the tropics, 1st edn (Great Britain: John Willey and Sons), 8p.

Lillesand Thomas M and Kiefer Ralph W 2000 Remote sensing and image interpretation (USA: John Willey \& Sons, Inc.), pp. 479-482.

Mashayekhan A and Honardoust F B 2011 Multi-criteria evaluation model for desertification hazard zonation mapping using GIS (Study Area: Trouti Watershed, Golestan, Iran); J. Rangeland Sci. 1(4) 331-339.

MA Millennium Ecosystem Assessment 2005 Ecosystems and human well-being: Desertification synthesis; World Resources Institute, Washington, DC.

McNamara J P, Chandler D, Seyfried M and Achet S 2005 Soil moisture states, lateral flow, and stream flow generation in a semi-arid, snowmelt-driven catchment; J. Hydrol. Process. 19 4023-4038, doi: 10.1002/hyp.5869.

Mukaidono M 2001 Fuzzy Logic for Beginners; Word Scientific, NY, 103p.

Reynolds J F, Smith D M S and Lambin E F 2007 Global desertification: Building a science for dryland development; Science 316 847-851.

Sasikala K R, Petrou M and Kittler J 2001 Fuzzy classification with a GIS as an aid to decision making; J. Fuzzy Sets Syst. 118 121-137.

Seyfried M S, Grant L E, Marks D, Winstral A and McNamara J 2009 Simulated soil water storage effects on streamflow generation in a mountainous snowmelt environment, Idaho, USA; J. Hydrol. Process. 23 858-873, doi: 10.1002/hyp.7211.

Stieglitz M, Shaman J, McNamara J, Engel V, Shanley J and Kling G W 2003 An approach to understanding hydrologic connectivity on the hillslope and the implications for nutrient transport; Global Biogeochem. Cycles 17(4) 1105p, doi: 10.1029/2003GB002041.

Summerfield M A 1997 Global Geomorphology; Longman, New York, 537p.

Townsend W N 1973 An introduction to the scientific study of the soil; Edward Arnold, London, pp. 161-172.

Tucker C J 1979 Red and photographic infrared linear combinations for monitoring vegetation; Rem. Sens. Environ. 8 127-150.

Tucker C J, Newcomb W W, Los S O and Prince S D 1991 Mean and inter-year variation of growing-season normalized difference vegetation index for the Sahel 1981-1989; Int. J. Rem. Sens. 12 1113-1115.

UNCCD United Nations Convention To Combat Desertification 1994 Elaboration of an International Convention to combat desertification in countries experiencing serious drought and/or desertification, particularly in Africa; U.N.Doc.A/AC/241/27, 33 I.L.M. 1328, United Nations.

UNCCD United Nations Convention To Combat Desertification 2008 Desertification - Coping with today's global challenges in the context of the strategy of the UNCCD. 
UNEP United Nations Environmental Programme 1997 The World Atlas of Desertification (eds) Middleton and Thomas D, Arnold, Great Britain, SBN 0340691662.

USDA United States Department of Agriculture 1999 Soil taxonomy: A basic system of soil classification for making and interpreting soil surveys; http://soils.usda.gov/ classification.

Velayutham M, Mandal D K, Mandal C and Sehgal J 1999 Agro-ecological subregions of India for planning and development, NBSS \& LUP Nagpur 35 88p.
Wischmeier W H 1974 New developments in estimating water erosion; 29th Annual Meeting Soil Conservation Society of America, Syracuse, New York, pp. 179-186.

Yang X and Hodler T 2000 Visual and statistical comparison of surface modeling techniques for point based environment data; J. Cartography and Geographic Inform. Sci. 27(2) 165-175.

Zlateva P, Kirov G and Stoyanov K 2005 Fuzzy logic application for eco-tourism potential assessment of villages; Automatics 83 Informatics 4 20-23.

MS received 23 August 2012; revised 11 February 2013; accepted 25 February 2013 